\title{
A comparison of mindfulness-based stress reduction and an active control in modulation of neurogenic inflammation
}

\author{
Melissa A. Rosenkranz ${ }^{1}$, Richard J. Davidson ${ }^{1,2,3}$, Donal G. MacCoon ${ }^{1}$, John F. Sheridan ${ }^{4}$, \\ Ned H. Kalin ${ }^{3}$, and Antoine Lutz ${ }^{1}$ \\ ${ }^{1}$ Waisman Laboratory for Brain Imaging \& Behavior and Center for Investigating Healthy Minds, \\ University of Wisconsin-Madison, 1500 Highland Avenue, Madison, Wisconsin 53705 \\ ${ }^{2}$ Laboratory for Affective Neuroscience, University of Wisconsin-Madison, 1202 W. Johnson St., \\ Madison, Wisconsin 53706 \\ ${ }^{3}$ Department of Psychiatry, University of Wisconsin-Madison, 6001 Research Park Boulevard, \\ Madison, Wisconsin 53719 \\ ${ }^{4}$ Department of Oral Biology and Department of Molecular Virology, Immunology and Medical \\ Genetics, Ohio State University, 305 W. 12th Ave., Columbus, Ohio 43210
}

\begin{abstract}
Psychological stress is a major provocative factor of symptoms in chronic inflammatory conditions. In recent years, interest in addressing stress responsivity through meditation training in health-related domains has increased astoundingly, despite a paucity of evidence that reported benefits are specific to meditation practice. We designed the present study to rigorously compare an 8-week Mindfulness-Based Stress Reduction (MBSR) intervention to a well-matched active control intervention, the Health Enhancement Program (HEP) in ability to reduce psychological stress and experimentally-induced inflammation. The Trier Social Stress Test (TSST) was used to induce psychological stress and inflammation was produced using topical application of capsaicin cream to forearm skin. Immune and endocrine measures of inflammation and stress were collected both before and after MBSR training. Results show those randomized to MBSR and HEP training had comparable post-training stress-evoked cortisol responses, as well as equivalent reductions in self-reported psychological distress and physical symptoms. However, MBSR training resulted in a significantly smaller post-stress inflammatory response compared to HEP, despite equivalent levels of stress hormones. These results suggest behavioral interventions designed to reduce emotional reactivity may be of therapeutic benefit in chronic inflammatory conditions. Moreover, mindfulness practice, in particular, may be more efficacious in symptom relief than the well-being promoting activities cultivated in the HEP program.
\end{abstract}

\section{Introduction}

Psychological stress is a potent trigger of inflammation (Welk et al., 2008; Steptoe et al., 2007; Pace et al., 2009) and as such, individuals suffering from chronic inflammatory conditions frequently turn to stress reduction methods in search of relief. Recent statistics

\footnotetext{
(C) 2012 Elsevier Inc. All rights reserved.

Address Correspondence to: Melissa A. Rosenkranz, University of Wisconsin-Madison, Waisman Laboratory for Brain Imaging and Behavior, 1500 Highland Avenue, Madison, WI 53705, marosenk@wisc.edu, Phone: 608-262-5050, Fax: 608-262-9440.

Publisher's Disclaimer: This is a PDF file of an unedited manuscript that has been accepted for publication. As a service to our customers we are providing this early version of the manuscript. The manuscript will undergo copyediting, typesetting, and review of the resulting proof before it is published in its final citable form. Please note that during the production process errors may be discovered which could affect the content, and all legal disclaimers that apply to the journal pertain.
} 
from the National Center for Complementary and Alternative Medicine (Barnes et al., 2007) show that conditions associated with inflammatory processes motivate nearly $40 \%$ of the use of complementary and alternative medicine (CAM) services. Among those using CAM services, most are pursuing approaches such as meditation, biofeedback, and relaxation, which influence the body via the brain.

The ability of the brain to modulate the immune system is essential in anticipating and coordinating an effective immune response. Neural regulation of immune function, particularly inflammation, in barrier tissues is especially important. Barrier tissues are tissues that interface between the external and internal environments, such as the skin and the gastrointestinal, respiratory, and urogenital tracts. These tissues are the first line of defense against invading pathogens and the inflammatory response is one of the primary means of resisting infection once a pathogen has circumvented the physical barrier (Kupper $\&$ Fuhlbrigge, 2004; Cua \& Tato, 2010). Therefore, it is not surprising that barrier tissues are highly susceptible to stress- and emotion-related inflammation, since through the lens of evolution, it would seem that stress is an indicator of threat and the increased likelihood for bodily injury and pathogenic exposure (Kupper \& Fuhlbrigge, 2004; Cua \& Tato, 2010; Hart \& Kamm, 2002; Arck et al., 2006; Liu et al., 2002).

The skin offers an appealing laboratory in which to examine stress modulation of barrier tissue inflammation. It has a surface area of approximately $1.5-2 \mathrm{~m}^{2}$ in the average adult, rivaled only by the intestines and lungs in exposed surface area (Bender \& Bender, 1995). Exposed surface area is vulnerable to pathogenic damage, and therefore requires close monitoring by the brain. Indeed, the skin has, on average, more than 500 nerve endings per square inch (McArthur et al., 1998), allowing for its rapid communication with the central nervous system (CNS) and intimate neural regulation.

Though advantageous in some regards, a high degree of neural input may also increase the vulnerability of the skin to inflammatory dysregulation. During psychological stress, inflammatory neuropeptides (e.g. substance P (SP) and calcitonin gene-related peptide (CGRP)) are released from the terminals of sensory nerves (Pavlovic et al., 2008; Peters et al., 2004). These neuropeptides act on the local immune cells and vasculature, in concert with norepinephrine released from local sympathetic nerves (Saint-Mezard et al., 2003; Banik et al., 2001; Drummond, 1995; Lin et al., 2003), to evoke an inflammatory response that is referred to as neurogenic. Indeed, stress-evoked immune changes that contribute to symptom onset and exacerbation have been documented in several inflammatory skin diseases (reviewed in Buske-Kirschbaum \& Hellhammer, 2003; Wright et al., 2005) including psoriasis (Buske-Kirschbaum et al., 2007), atopic dermatitis (Buske-Kirschbaum et al., 2002), eczema (Bockelbrink et al., 2006), alopecia (Kim et al., 2006) and urticaria (Barrino et al., 2006). As such, the role of cutaneous nerves in stress-related inflammation has become a bigger research focus (Arck et al., 2006; Arck \& Paus, 2006; Kleyn et al., 2008; Pavlovic et al., 2008; Peters et al., 2006; Scholzen et al., 1998). From this growing body of work, capsaicin-sensitive sensory nerves and the neuropeptides they contain, together with local sympathetic nerves and mast cells, have been identified as important contributors to the relationship between psychological stress and symptom expression in inflammatory skin diseases. Indeed, in a recent study, Pavlovic and colleagues (2008) show that stress-evoked symptom exacerbation in dermatitis was dependent upon the activation of sensory neuropeptide receptors. Therefore, in the present study, a capsaicin-induced inflammatory response and an acute laboratory stressor were used as a model in which to investigate psychological stress and neurogenic inflammation in the skin.

Acute laboratory stressors that incorporate uncontrollability and social-evaluative threat have been reliably shown to evoke increases in measures of physiological stress and 
peripheral inflammation (Dickerson \& Kemeny, 2004; Dickerson et al., 2009; Gruenewald et al., 2004; Kirschbaum et al., 1993; Pace et al., 2009; Rohleder et al., 2006). As these features characterize some of the most commonly experienced daily stressors (e.g. workrelated, financial, travel-related, social/peer pressure), laboratory manipulations, such as the Trier Social Stress Test (TSST; Kirschbaum et al., 1993), that incorporate uncontrollability and social-evaluative threat are good choices to model the types of real-world stressors that contribute to symptom exacerbation in those with chronic inflammation. For this reason, we used the TSST to evoke acute psychological stress in this study.

Interest in meditation as a method to reduce psychological stress has grown substantially in the last several years (Barnes et al., 2007; Kabat-Zinn et al., 1998; Carlson et al., 2004; Pace et al., 2009; Kemeny et al., 2011). Despite the rapid increases in usage and spending on these therapeutic techniques, relatively little is known about the mechanisms or specificity of their efficacy. Mindfulness-based stress reduction (MBSR) is the dominant form of meditation training in healthcare settings in the United States (for a recent review see Chambers et al. 2009). Mindfulness was initially defined, in the context of MBSR, as "paying attention in a particular way: on purpose, in the present moment, and nonjudgmentally" (Kabat-Zinn, 1990). More specific, operational definitions of mindfulness practice have since been proposed (e.g. Bishop et al., 2004; Chambers et al., 2009) and continue to be developed (Kabat-Zinn, 2011; Grossman \& Van Dam, 2011). In brief, mindfulness practice cultivates an open, and accepting awareness of whatever is occurring in the present moment, without reacting or being absorbed in the contents of the experience (Chambers et al., 2009; Kabat-Zinn, 2011). Thus, the aim of this training is not to explicitly change the content of experience, but rather to change one's relationship to it.

Since its inception in 1979, MBSR has shown benefit in alleviating symptoms of a broad array of conditions from anxiety disorders to diabetes (Gregg et al., 2007; Ma \& Teasdale, 2004; Grossman et al., 2007; Pradhan et al., 2007; Speca et al., 2000; Kabat-Zinn et al., 1998). However, across the rapidly growing number of published empirical reports describing the use of MBSR as an intervention, there is little evidence for its efficacy relative to other treatments or for mindfulness practice per se as a specific mechanism for change. The vast majority of studies have evaluated the effectiveness of MBSR based on pre to post-training changes and wait-list or no treatment comparison groups. While these studies certainly establish that MBSR is effective across a wide range of populations and conditions and, when added to standard treatment, can improve some health outcomes, they are not designed to test whether MBSR is superior to other treatments or whether mindfulness, itself, is the active ingredient leading to these positive outcomes (for further discussion see MacCoon et al., 2012).

Therefore, this experiment was designed to investigate the ability of mindfulness training to buffer the effects of psychological stress and dermal neurogenic inflammation in healthy individuals. It is important to note this experiment was not designed to test the impact of an acute laboratory stressor on the inflammatory response or vice versa. However, these effects have been well-documented elsewhere (e.g. Brydon et al., 2009; Pace et al., 2009; Rohleder et al., 2006; Pavlovic et al., 2008; Carroll et al., 2011). In order to address questions of specificity of the benefits of mindfulness training, we compared MBSR to an active comparison condition, designed to carefully match MBSR in non-specific factors that promote wellbeing. We predicted that, in measures of neurogenic inflammation and physiological stress, those randomized to MBSR training would show a less robust posttraining stress and inflammatory response, relative to pre-training responses and relative to those randomized to the active comparison condition. Furthermore, we predicted that time spent practicing MBSR, but not HEP, should predict the relative reductions in these measures. Laboratory assessments included the induction of experimental inflammation and 
psychological stress, as well as the collection of biological measures for quantification of stress and inflammation and the collection of standard self-report measures (see MacCoon et al., 2012). Laboratory assessments were performed within 4 weeks before the start of training (T1) and within 4 weeks after completion of training (T2). All measures were collected again at 4 months after completion of training (T3).

\section{Methods}

\section{Participants}

Participants included 49 community volunteers (10 male) between the ages of 19 and 59 ( $M$ $=45.89$ years, $S D=10.92)$, recruited through advertisements in local newspapers. The groups did not differ with respect to age $(t(47)=1.47, p>.1$; HEP: $M=48.9$ years, MBSR: $M=44.4$ years). All participants were screened and criteria for exclusion included: significant previous experience with meditation or other mind-body techniques (e.g. tai-chi, Qigong), remarkable exercise habits (engagement in moderate sport or recreational activities $>5$ times per week; engagement in vigorous sport or recreational activities $>4$ times per week; inability to walk), use of psychotropic or steroid drugs, night-shift work, diabetes, peripheral vascular disease or other diseases affecting circulation (e.g. Raynaud's disease), needle phobia, pregnancy, current smoking habit, alcohol or drug dependency, inability to attend weekly class and full-day group sessions (for full details, see MacCoon et al., 2012). This experiment took place in the context of a larger set of experiments in the same individuals, that examined the effects of our interventions on a variety of outcome measures including attention and emotion regulation. For this reason, we were constrained in the number and type of measures we could collect, to minimize participant burden, and in the characteristics of the sample we recruited. Results from these experiments will be reported elsewhere.

\section{Interventions}

Participants were randomly assigned to either mindfulness training or training in our active comparison condition after completion of the T1 laboratory assessments. MBSR training consists of continuous focused attention on the breath, bodily sensations and mental content while in seated postures, walking, and yoga (Kabat-Zinn, 1990). In the current study, MBSR instruction was modeled after the intervention developed by Jon Kabat-Zinn at the University of Massachusetts Medical Center (Kabat-Zinn, 1990) and was delivered by two experienced and certified MBSR instructors over 8 weekly $2.5 \mathrm{~h}$ sessions and one full-day session. In addition, daily at-home practice was assigned that ranged in duration from 45 to $60 \mathrm{~m}$.

In order to isolate mindfulness as the agent of change, we designed an active comparison intervention to control for the aspects of MBSR that are known to promote positive outcomes, but are not specific to mindfulness such as a supportive group atmosphere, expert instruction, and engaging in activities that are believed to provide benefit. Our active comparison condition - the Health Enhancement Program (HEP) - matched MBSR in structure, instructor expertise, and content (see MacCoon et al., 2012 for a detailed description). Like MBSR, HEP consisted of four components: (1) physical activity (e.g. walking) (2) balance, agility, and core strength (3) nutritional education and (4) music therapy. Each of these components was chosen to match the collateral benefits that MBSR may produce that are not unique to mindfulness. For example, physical activity with a focus on walking, was selected to control for the physical benefits of walking meditation. Each component was delivered by an expert in the respective practice, over 8 weekly $2.5 \mathrm{~h}$ sessions and one full-day session. Like those participating in MBSR training, HEP participants were assigned 45 to $60 \mathrm{~m}$. of daily at-home practice. 


\section{Experimental manipulations}

An illustration of the experimental paradigm can be found in figure 1. A modified version of the Trier Social Stress Test (TSST; Kirschbaum et al., 1993) was used to induce psychological stress in our participants. Briefly, the stress test consisted of a 5-minute impromptu speech on a given topic followed by 5 minutes of mental arithmetic. The stress test was performed standing in front of a microphone before a panel of two (one male, one female) judges and a video camera. Participants were given 3 minutes to prepare their speech after the topic was revealed, but were not allowed to use their notes during the speech. The speech topic and mental arithmetic task were changed at each assessment. This version differs from the original in that the speech preparation time is 7 minutes shorter.

A local, neurogenic inflammatory response was induced in forearm skin using topical capsaicin (.1\%) cream. Capsaicin is a naturally occurring compound found in hot peppers that imparts their "hotness". Capsaicin causes depolarization of predominantly C-fiber type sensory neurons by binding to vanilloid receptors (sub-type 1; TRPV1). In addition to the afferent impulse this evokes, a descending impulse also results, moving down branches of the same sensory nerve (antidromic stimulation), causing neuropeptide release from nearby terminals. These neuropeptides (including SP, CGRP, somatostatin, neurokinin A) cause inflammation both via actions on the local vasculature, evoking vasodilation (the flare response) and increased vascular permeability, and via activation of local immune cells (e.g. mast cells), stimulating their release of pro-inflammatory immune mediators (Lotz et al., 1988; Schmelz et al., 1997).

\section{Self-report measurements}

Self-reported physical and psychological symptoms were measured at each assessment at baseline (i.e. not pre- and post-stressor). We used the Symptom Checklist-90-R (SCL-90-R; Derogatis, 1983) and the Medical Symptoms Checklist (MSC; Travis, 1977) to assess mental and physical symptoms. The 90-item SCL-90-R consists of nine subscales and three global scales. The Global Severity Index (GSI) provides a measure of overall psychological distress and has demonstrated sensitivity to change and adequate internal consistency (Thompson, 1989). The depression, anxiety, and hostility subscales also were used (Cronbach's $a=.90, .85$, and .84 respectively; test-retest reliabilities are $r=.82, .80$, and .78 respectively).

The MSC measures the number of medical symptoms participants' experienced as problems in the last month. While the MSC has demonstrated sensitivity to change in past studies of MBSR (Kabat-Zinn, 1982), no further psychometric data is available.

\section{Biological measurement}

Inflammation-In order to obtain molecular measures of local inflammation, suction blisters were raised on the volar forearm, just below the cubital fossa. Vacuum pressure (maximum $508 \mathrm{mmHg}$ ) was applied to the skin through an acrylic template with eight $6 \mathrm{~mm}$ holes. The forearm area, including the blister template, was wrapped in a heating pad, to facilitate the formation of the blisters ${ }^{1}$, which took an average of $53.6 \mathrm{~m}$ (range 28 to 86 ). Following removal of the vacuum pressure, fluid was collected from 4 blisters using a tuberculin syringe and was immediately frozen at $-80^{\circ} \mathrm{C}$. Capsaicin cream $(.3 \mathrm{ml}$.) was applied around the perimeter of, but not touching, the remaining four blisters. The cream was removed $45 \mathrm{~m}$ after application. The fluid from the remaining 4 blisters was extracted approximately $30 \mathrm{~m}$ following the TSST and was frozen at $-80^{\circ} \mathrm{C}$.

\footnotetext{
${ }^{1}$ Pilot testing determined that use of heat to facilitate blister formation did not affect the levels of cytokines in the blister fluid at baseline or following capsaicin exposure.
} 
Enzyme-linked immunosorbent assay (R \& D Systems, Minneapolis, MN) was used to quantify levels of tumor necrosis factor alpha (TNF-a) and interleukin (IL)-8 in the blister fluid in the laboratory of Dr. John Sheridan at Ohio State University. TNF-a and IL-8 were chosen because levels in skin wounds of both cytokines have been shown to be sensitive to modulation by psychological stress (Glaser et al., 1999). In addition, neuropeptides (e.g. SP) released from capsaicin-sensitive nerve endings trigger release of these cytokines from local immune cells (Cuesta et al., 2002; Gibbs et al., 2001; Okayama et al., 1998; Park et al., 2004; Serra et al., 1994).

In addition to molecular measures of inflammation, capsaicin-induced flare size was also measured to obtain an index of local neurogenic inflammation (Petersen et al., 1997). A flare response is the area of redness or erythema that extends beyond the area covered by capsaicin, which is caused by nerve-mediated vasodilation (Helme \& McKernan, 1985). The neurogenic nature of the flare response has been demonstrated in studies where the flare response was abolished or greatly attenuated by impairing nerve function (Bjerring \& Arendt Nielsen, 1990; Izumi \& Karita, 1992). Digital photographs were taken immediately after the TSST and at subsequent 10-minute intervals for 30 minutes to capture the development of the flare. The perimeter of the flare was digitally traced on each photo and the flare area was calculated using Canvas software (ACD Systems, Inc., Vancouver, B.C.). Individuals tracing the flare response were blind to group status. Efforts were made to standardize the distance and angle of the camera relative to the arm. In addition, remaining differences in image scale were corrected by dividing the flare area by the area of a circular sticker placed on the arm, next to the flare, that was identical for every participant.

Cortisol-Salivary cortisol was collected using the Salivette device (Sarstedt, Inc., Nümbrecht, Germany) as an index of the magnitude of stress response. Saliva samples were collected after the 20-minute rest period, immediately before the TSST (after the blisters were formed), immediately after the TSST, and at subsequent 10-minute intervals for 30 minutes -6 samples per assessment in total. In addition, participants collected saliva samples at home 5 times per day (awakening, $30 \mathrm{~m}$ post-awakening, before lunch, $3 \mathrm{pm}$, and before bed) for 3 days to provide measures of cortisol diurnal rhythm. Saliva samples were frozen at $-80^{\circ} \mathrm{C}$ until assayed. Cortisol in saliva samples was quantified using Enzyme Immunoassay (Salimetrics, Inc., State College, PA.).

\section{Statistical analyses}

Paired samples t-tests were used to determine if we successfully induced inflammation and psychological stress. Blister fluid cytokine levels were used as an indicator of inflammation and salivary cortisol level was used as an indicator of stress response magnitude. Values of blister fluid cytokines, obtained both pre- and post-challenge, were log-transformed in order to correct for skewed distributions. Log-transformed pre- and post-challenge values of TNF$a$ and IL-8 were compared at each time point. Raw cortisol values obtained immediately before the TSST (baseline) were compared to raw values obtained from the sample collected 10 min. after the TSST, for each assessment.

Repeated measures analysis of variance (ANOVA) was used to determine the effect of MBSR and HEP interventions on flare size, blister fluid cytokine levels and cortisol response to stress, diurnal cortisol slope, total daily cortisol output, and self-reported physical and mental symptoms from T1 to T2. To address secondary hypotheses related to the persistence of training effects, we repeated these analyses comparing T1 to T3 measures. For flare size and cortisol response, the repeated measures variable was time with 2 levels: T1 and T2 (or T3). For blister fluid cytokines, two repeated measures variables were included in the model: challenge with 2 levels (pre and post), and time with 2 levels (T1 and 
T2 or T3). Group (HEP and MBSR) was included as a between-subjects variable in all models. Cortisol response to challenge was captured in a summary variable computed as the peak of response minus the baseline sample. Flare response to capsaicin was reflected in the summary variable area under the curve with respect to ground (AUC), described by Pruessner et al. (2003). These variables were used to evaluate the change in flare size and TSST cortisol response over time. To evaluate changes in diurnal cortisol pattern, a slope variable was computed for each assessment by regressing the log-transformed mean (across the 3 days of collection) cortisol values, on mean times that the samples were collected, where the resulting unstandardized regression coefficients are the slope variables. In addition, AUC of daily cortisol output was computed to reflect total output of cortisol across the day and log-transformed to normalize its distribution. Log-transformed pre- and postchallenge blister fluid cytokine levels were used to evaluate the change in TNF- $a$ and IL-8 across challenge and time.

To examine the impact of practice on cortisol and inflammatory responses, we tested the relationship between self-reported time spent in practice and each of the outcome measures and whether the effects of practice on the outcome variables differed for the two interventions. First, we compared the groups based on the amount of formal practice (in minutes) reported, both during the 8-week intervention and during the 4-mo following the intervention, using independent samples t-tests. We then used a multiple regression approach to examine the predictive utility of practice in determining the degree of change that occurred in each of our outcome variables as a result of the interventions. By using a hierarchical modeling strategy we were able to evaluate both the effect of practice on our outcome variables (with group held constant), and the degree to which the effect of practice on the outcome variables differed by group. The dependent variables in these regression analyses represented the change from $\mathrm{T} 1$ to $\mathrm{T} 2 \mathrm{in}$ each of the outcome variables. For blister fluid TNF- $a$ and IL-8, change scores were created by first regressing pre-challenge values on post-challenge values at each time point. The residual variance from this regression reflected the increase in cytokine levels in response to challenge. This residual variance at $\mathrm{T} 1$ was subtracted from the residual variance at $\mathrm{T} 2$ and $\mathrm{T} 3$ to create a change score for each cytokine. Percentage change variables were created to evaluate the effect of practice on both flare size, cortisol response, and diurnal cortisol variables. Percent change (decrease) was computed by subtracting the $\mathrm{T} 2$ and $\mathrm{T} 3$ variable from the $\mathrm{T} 1$ variable and then dividing the resulting difference score by $\mathrm{T} 1$.

\section{Results}

\section{Manipulation Checks: Stress and inflammation induction}

Results of the paired t-tests verified the effectiveness of our experimental manipulations. Both pre- and post-intervention, blister fluid cytokine and salivary cortisol levels were significantly increased after the application of capsaicin and completion of the TSST (see figures $2 \& 3)$. Mean TNF- $a$ levels from pre- to post-challenge increased $19 \%$ at T1 $(t(46)=$ $-8.09, p<.001)$ and $22 \%$ at T2 $(t(42)=-8.89, p<.001)$. Mean IL-8 levels increased $13 \%$ at $\mathrm{T} 1(t(41)=-6.33, p<.001)$ and $15 \%$ at $\mathrm{T} 2(t(41)=-7.99, p<.001)$. Mean cortisol levels increased from pre- to post-challenge $168 \%$ at $\mathrm{T} 1(t(47)=-6.01, p<.001)$ and $84 \%$ at $\mathrm{T} 2$ $(t(42)=-4.21, p<.001)$.

\section{Primary analyses: Effects of the intervention}

Flare-Repeated measures analysis of variance (ANOVA) revealed a significant main effect of time $(F(1,27)=31.74, p<.001)$ and a significant group by time interaction $(F(1$, $27)=10.07, p=.004$ ) on flare size. Examination of the main effect of time revealed that, across groups, flare size showed a significant increase from T1 to T2 $(t(28)=4.99, p<$. 
001). However, the magnitude of increase was not constant across groups. At T1, the HEP and MBSR groups did not differ $(t(35)=-.41, p=.686)$. At T2, flare size for the MBSR group increased only slightly with respect to $\mathrm{T} 1(t(13)=-1.83, p=.09$ and was significantly smaller than that of the HEP group $(t(42)=-2.98, p=.005)$, see figure 4$)$, for which flare size increased significantly between assessments $(\mathrm{t}(14)=-6.00, p<.001)$.

Blister fluid cytokine levels-Repeated measures ANOVA revealed a significant main effect of challenge $(F(1,35)=58.58, p<.001)$ on blister fluid levels of IL-8. No significant effects of time, group, or interactions among challenge, time, or group were observed.

The pattern of results for TNF- $\propto$ levels in blister fluid were similar to those observed for IL-8. Repeated measures ANOVA showed significant main effects of challenge $(F(1,41)=$ $58.16, p<.001)$ and time $(F(1,41)=11.35, p<.01)$, such that T2 TNF- $\propto$ levels were greater than levels at T1. No interactions or main effects of group were found ${ }^{2}$.

Cortisol-Results of a repeated measures ANOVA revealed a significant main effect of time for cortisol response (peak-baseline; $F(1,34)=5.16, p=.03$ ) to the TSST (see figure 3 ). There was neither a significant effect of group $(\mathrm{F}(1,34)=1.69, p=.20)$, nor a group by time interaction $(\mathrm{F}(1,34)=.03, p=.86)^{3}$ for stress-evoked cortisol response. However, MBSR and HEP training did differentially impact the diurnal rhythm of cortisol. At T1, the slope of the decline in cortisol produced across the day did not differ between the two groups $(p=.53)$, whereas after the intervention, there was a non-significant trend for the slope to be steeper for the MBSR group and less steep for the HEP group at T2 (group $\times$ time interaction; $\mathrm{F}(1,50)=2.52, p=.12$ ), that becomes a significant difference at $\mathrm{T} 3$ (see secondary analyses below). On the other hand, cortisol AUC showed a main effect of group $(\mathrm{F}(1,45)=8.96, \mathrm{p}=.004)$, where MBSR had lower daily cortisol output across assessments, but no main effect of time $(F(1,45)=.10, p=.75)$ or group $\times$ time interaction $(F(1,45)=.30$, $\mathrm{p}=.59)$.

Self-report-Results of repeated measures ANOVA for the Global Severity Index (GSI) of the SCL-90 showed a main effect of time $(F(1,47)=7.97, p=.007)$, indicating that GSI scores decreased over time. No main effect of group or interaction between group and time was observed, suggesting that the groups did not differ in the extent or direction of change from $\mathrm{T} 1$ to $\mathrm{T} 2$ on this measure. Similarly, a main effect of time was present for anxiety symptoms $(F(1,47)=7.18, p=.01)$, where both groups reported less anxiety at $\mathrm{T} 2$ compared to T1, but again, no main effect of group or interaction between group and time was observed. The same pattern of results emerged for physical symptoms, reported on the MSC, where both groups reported fewer problematic physical symptoms at $\mathrm{T} 2$ relative to $\mathrm{T} 1$ $(F(1,51)=6.16, p=.016)$, but the groups did not differ in overall reported symptoms or the pattern of change from T1 to T2. No significant effects were found for self-reported depression or hostility.

\section{Effects of practice}

Independent samples t-tests revealed that the groups did not differ with respect to the amount of practice they reported during the 8-week intervention $(t(51)=1.22, p=.23)$ with the MBSR group reporting approximately $236 \mathrm{~min}(4 \mathrm{~h})$ of formal practice per week and the HEP group reporting approximately $212 \mathrm{~min}(3.5 \mathrm{~h})$ per week. Multiple regression analyses were used to determine if practice was a good predictor of the change in the outcome variables in response to the intervention and if the effect of practice was similar for HEP and

\footnotetext{
${ }^{2}$ There were no group differences pre-challenge at T2 or T3 for either IL-8 or TNF-a.

${ }^{3}$ There were no pre-challenge differences in cortisol at $\mathrm{T} 2$ or $\mathrm{T} 3$.
} 
MBSR groups ${ }^{4}$. Only daily cortisol release (AUCg) showed a significant relationship with practice across groups $(s r=-.41, p=.006)$, where the more a participant reported practicing either HEP or MBSR training, the larger the decrease in cortisol between T1 and T2.

However, when interactions between group and practice were examined, results showed that the effect of practice on blister fluid levels of TNF-a differed by group ( $s r=-.35, p=.028)$. While greater practice was associated with a decrease in TNF-a levels from pre- to posttraining in the MBSR group, more practice predicted greater TNF-a levels in the HEP group. The zero-order correlations between change in cytokine level and practice for each group individually were not significant (MBSR: $r=-.28, p=.16$; HEP: $r=.42, p=.12$ ). Although the analogous interaction was not significant for IL-8 ( $s r=-.17, p=.334)$, the relationship showed the same pattern (see figure 5). Interactions between group and practice were not observed for any other outcome variables.

\section{Secondary Analyses: Persistence of training effects}

Stress and inflammation induction-At T3, our experimental manipulations continued to be successful. Mean TNF-a levels increased 37\% from pre- to post-challenge at T3 (tt46) $=-12.00, p<.001)$ and mean IL-8 levels increased $27 \%(t(44)=-10.54, p<.001)$. Mean cortisol levels increased $99 \%$ from pre- to post-challenge at this assessment $(t(45)=-4.73, p$ $<.001)$.

Effects of the intervention-As was the case with change from $\mathrm{T} 1$ to $\mathrm{T} 2$, flare size increased significantly from $\mathrm{T} 1$ to $\mathrm{T} 3(\mathrm{~F}(1,27)=41.52, p<.001)$. However, unlike at $\mathrm{T} 2$, there was no difference in the magnitude of the increase between HEP and MBSR groups $(\mathrm{F}(1,27)=1.19, p=.29)$ and no overall group difference $(\mathrm{F}(1,27)=.033, p=.86)$. Blister fluid levels of TNF- $a$ and IL- 8 showed the expected effect of challenge, where cytokine levels were higher post-challenge than pre-challenge (TNF-a: $\mathrm{F}(1,34)=175.65, p<.001$; IL-8: $\mathrm{F}(1,28)=106.16, p<.001)$. However, unlike at T2, levels of both cytokines were lower at $\mathrm{T} 3$ than at T1 (TNF-a: $\mathrm{F}(1,34)=226.38, p<.001$; IL-8: $\mathrm{F}(1,28)=42.77, p<.001)$. There were no significant main effects of group or interactions with group for either cytokine.

Cortisol response to the TSST was lower at T3 compared to T1 $(\mathrm{F}(1,38)=11.83, p=.001)$ for both groups and the groups did not differ in overall cortisol response $(\mathrm{F}(1,38)=1.11, p$ $=.30$ ). However, when diurnal cortisol rhythm was examined, the trend toward a steeper slope in the MBSR group and less steep slope in the HEP group became more pronounced $(\mathrm{F}(1,51)=4.91, p=.03)$. In contrast, the group difference in daily cortisol output (AUC) was no longer present $(\mathrm{F}(1,43)=2.36, \mathrm{p}=.13)$.

The pattern of change in self-reported mental and physical symptoms from T1 to T3 was nearly identical to that between T1 to T2. GSI scores $(\mathrm{F}(1,49)=6.29, p=.016)$, anxiety $(\mathrm{F}(1,49)=5.41, p=.024)$, and physical symptoms $(\mathrm{F}(1,50)=10.15, p=.002)$ decreased from T1 to T2 in both groups and there was no main effect of group or interaction between group and time for these measures. Symptoms of hostility showed this same pattern from T1 to T3 (main effect of time: $\mathrm{F}(1,49)=4.36, p=.042$ ). No significant main effects or interactions were observed for symptoms of depression.

Effects of practice-Independent samples t-tests revealed that the groups did not differ with respect to the amount of practice they reported in the 4 months following the

\footnotetext{
${ }^{4}$ Age was also examined as a possible covariate, but is not included in these analyses because it accounted for very little variance in the outcome measures.
} 
intervention $(t(49)=-1.44, p=.16)$, with the MBSR group reporting approximately 123 $\min (2 \mathrm{~h})$ of formal practice per week and the HEP group reporting approximately $162 \mathrm{~min}$ $(2.5 \mathrm{~h})$ per week. Amount of time spent practicing did not predict change from T1 to T3 in any of the variables measured (data not shown). When examined as a function of group, change in blister-fluid cytokine level from $\mathrm{T} 1$ to $\mathrm{T} 3$ showed the same relationship pattern with practice as it did immediately following the intervention, though neither interaction was significant (TNF-a: $s r=-.24, p=.13$; IL-8: $s r=-.05, p=.79$ ). Similarly, the relationship between change in flare size from $\mathrm{T} 1$ to $\mathrm{T} 3$ and practice showed a trend for a group difference (group $\times$ practice interaction: $s r=.35, p=.086$ ). However, the pattern of this effect was opposite to that observed with the cytokines, such that for the HEP group, more practice predicted a smaller increase in flare size at 4 mo., whereas for the MBSR group, more practice predicted a larger increase, though neither of the individual correlations was significant.

\section{Discussion}

By comparing the effects of MBSR training to those of training in an active control intervention designed to promote well-being in ways that are common to many therapeutic interventions, we were able to discern benefits of MBSR that may be unique to mindfulness practice. The results of the present study showed that changes specific to mindfulness practice may reduce the development of cutaneous neurogenic inflammation and promote a more salubrious pattern of HPA-axis function, after non-specific therapeutic factors are controlled. We were successful in inducing both stress and inflammation at each assessment and the inflammatory response (both flare size and TNF- $\alpha$ levels) increased from T1 to T2. However, individuals randomized to MBSR training showed a smaller potentiation of the flare response and a steeper diurnal cortisol slope at post-training, relative to pre-training, than those randomized to HEP training. In contrast, cortisol response to the TSST declined across assessments in both groups. Interestingly, the relationship between practice and blister-fluid cytokine levels distinguished our groups, such that greater time spent engaged in MBSR practice predicted lower blister-fluid cytokine levels, whereas the HEP group showed the opposite pattern.

The decline in cortisol slope from pre- to post-MBSR training is consistent with a more healthy physiological profile. A large body of research indicates that a steeper diurnal cortisol slope is salubrious, predicting a wide range of positive mental and physical health determinants including higher cognitive function (Stawski et al., 2011), greater regulation of negative affect (Urry et al., 2006), and increased length of cancer survival (Cohen et al., 2012). In contrast, a flattened cortisol slope has been associated with myriad deleterious conditions including depression (Keller et al., 2006), chronic stress (Adam \& Gunnar, 2001), atherosclerosis (Matthews et al., 2006) and cardiovascular disease mortality (Kumari et al., 2011), as well as fatigue, disease severity, and mortality in breast cancer (Bower et al., 2005; Abercrombie et al. 2004; Sephton et al., 2000). It is unclear why cortisol slope tends to flatten from pre- to post-HEP training, given that both interventions resulted in comparable reductions in general psychological distress, anxiety symptoms, and problematic medical symptoms between T1 and T2. Indeed, there is evidence that HEP was superior to MBSR in some domains (see MacCoon et al., 2012). This observation will require follow-up in future experiments that use this active comparison group.

Despite the group difference in change in cortisol slope following training, we did not find a group difference in change in cortisol reactivity to the TSST. Cortisol response diminished across time for both groups to a similar extent. There is precedence for this lack of convergence between diurnal cortisol rhythm and cortisol response to challenge. For example, Spiegel and colleagues (2006) found no association between daytime cortisol slope 
and cortisol response to either CRF infusion or the TSST. We cannot determine whether the decline in cortisol response from pre- to post-training is due to habituation to the stressor or to an effect of the intervention or both. However, based on existing data on the habituation of the cortisol response to repeated TSSTs, it seems likely that the interventions caused some reduction in cortisol responsivity, above and beyond simple habituation. Schommer and colleagues (2003) reported a reduction in cortisol response of about $15 \%$ when repeated TSSTs were spaced 1 week apart. In the current study, the peak was diminished by about $31 \%$ over an 8-12 week span, suggesting that the reduction in response may reflect both habituation and an effect of the interventions.

The potentiation of the inflammatory response from pre- to post-training was unexpected. Rather, we predicted an attenuated response at T2 for the MBSR group and no change for the HEP group. However, on post-hoc examination, it seems that the observed potentiation for the HEP group reflects, at least in part, an increase in skin irritability that accompanies colder, drier winter weather (Uter et al., 2008) and the lack of increase in the MBSR group reflects a decrease from this seasonal variation. Indeed, average temperature at $\mathrm{T} 1$ was $66^{\circ} \mathrm{F}$ (range: $49-81$ ), at $\mathrm{T} 2$ was $36^{\circ} \mathrm{F}$ (range: $17-51$ ), and at $\mathrm{T} 3$ was $35^{\circ} \mathrm{F}$ (range: 6-69) and mean daily temperature accounted for $8 \%$ of the variance in flare size $(r=-.29, \mathrm{p}=.009)$.

The flare response is a relatively pure measure of neurogenic inflammation (Bjerring \& Nielsen, 1990; Izumi \& Karita, 1992), which is thought to be a major factor in the stressresponsiveness of chronic inflammatory diseases (Rosenkranz, 2007; Black, 2002). The most direct effect of stress on neurogenic inflammation, in the time window captured in this study, is likely mediated by activation of the sympathetic nervous system. Norepinephrine (NE) is released from sympathetic nerve terminals in the skin in response to stress (SaintMezard et al., 2003). Sympathetic terminals in normal skin are found in close proximity to C-fibers and NE has been shown to sensitize these sensory nerve endings (Banik et al., 2001; Drummond, 1995). In inflamed skin, NE alone can activate C-fibers, causing afferent signaling and antidromic release of neuropeptides (Banik et al., 2004; Sato et al., 2003). Further, NE release from sympathetic nerves in the skin has been shown to directly modulate flare size in response to capsaicin. In an elegant study reported by Lin and colleagues (Lin et al., 2003), the spread of the flare response was shown to depend on NE activation of $a_{1}$-adrenergic receptors located on primary afferent fibers, while the antidromically-stimulated vasodilation near the area of capsaicin application was independent of sympathetic activity. This mechanism of stress-induced inflammatory exacerbation is consistent with the pathophysiological profile observed in some stressresponsive inflammatory skin diseases. Buske-Kirschbaum and colleagues have shown, for example, that individuals with psoriasis (Buske-Kirschbaum et al., 2006) and atopic dermatitis (Buske-Kirschbaum et al., 2002) have a greater increase in NE levels in response to psychological stress than healthy controls.

In the present study, MBSR training may have reduced sympathetic responsivity to the TSST, relative to the HEP group, resulting in decreased facilitation of the flare response. Unfortunately, we did not measure local release of NE or other indices of SNS activation, which strongly limits the conclusions that can be drawn about the mechanism of relative flare attenuation. Based on the salivary cortisol data, which did not show post-training group differences, it would appear that the stress response of both groups decreased to a similar extent. However, the SNS is much more sensitive than the HPA-axis and previous studies have found that the activity of these two systems is uncorrelated. Indeed, Schommer and colleagues (Schommer et al., 2003) directly compared SNS and HPA-axis responses to the TSST at 3 separate time points, each 4 wks apart. Though the activity in both pathways increased significantly in response to the stressor at each assessment, the magnitude of the cortisol response declined, while the magnitude of the NE response remained the same 
across time. As previously mentioned, this pattern is even more pronounced in chronic inflammatory diseases, where NE release in response to a psychological stressor is increased and cortisol release is decreased already at the first exposure, relative to healthy controls. This pattern has been observed in inflammatory diseases of several different types of tissues including the skin (Buske-Kirschbaum et al., 2006; Buske-Kirschbaum et al., 2002), joints (Härle et al., 2006), and gut (Straub et al., 2002). The lack of measurement of SNS activity is a limitation in the current study and should be included in future designs.

Despite the group difference in flare size at $\mathrm{T} 2$, we did not observe the predicted group difference in the change in release of TNF- $a$ and IL-8 in blister fluid. It is possible that the difference between groups as a result of the training was too subtle to be detected in cytokine levels. The cascade of interactions between inflammatory mediators and local immune cells, in response to capsaicin may have overwhelmed relatively subtle differences in the change in response to stress. On the other hand, the flare response is more directly influenced by changes in sympathetic activation. In addition, we may have failed to capture an existing difference in post-training cytokine levels in the narrow time window that we measured. The flare response progresses very quickly and had already begun to decline within our period of measurement. However, the cytokine response is likely to develop much more slowly and highlights another area where this design could be improved upon in future studies.

Although overall group differences in cytokine response to our interventions was absent, we did find that the groups differed in the degree to which practice was associated with a reduction in TNF-a level from pre to post-intervention. Greater time spent practicing mindfulness was associated with a larger decrease in TNF-a, whereas HEP practice tended to show the opposite relationship. These data corroborate findings from other studies that show the effects of mindfulness training are dependent on practice (Carmody \& Baer, 2008; Jha et al., 2010; Pace et al., 2009). Pace and colleagues (2009), for example, found that the reduction in psychological distress and stress-induced plasma IL-6, associated with meditation training, were only observed in those who reported practicing more than the median amount, whereas those below the median did not differ from controls on these measures. In addition, practice in both training modalities predicted a decline in daily cortisol output. The fact that we find that the effect of the interventions on the outcome variables is somewhat dependent on practice is encouraging and suggests that these are skills that require honing and to the extent that one develops their skill, it will influence their perception of and/or reaction to incoming information.

It is interesting to note that the attenuation of the flare and reduction in cytokine level with practice was less strong or absent at the 4 mo. follow-up. It is also noteworthy that selfreported weekly practice in both groups declined by nearly half in the months that followed the intervention, compared to practice time during the intervention. This suggests that the group meetings and teacher support were important for maintaining the physiological benefits of mindfulness practice. Indeed, the importance of a "sangha" or spiritual community is strongly emphasized by most meditation teachers.

Though these data are promising and suggest some specific domains in which mindfulness training may be beneficial, this study has several limitations. Because we needed to limit participant burden in the context of the larger set of experiments in which these individuals participated, we omitted a stress condition in the absence of inflammation and an inflammation condition in the absence of stress. As a result, we are unable to determine the interaction between stress and inflammation and the impact of the interventions on this interaction. Relatedly, the participants in this experiment were relatively healthy and not selected for chronic inflammation or stress, even though the populations to which we hope 
to apply these data include those with chronic stress and/or chronic inflammation. Therefore, the relevance of these data to clinical populations may be somewhat limited. In addition, the absence of measures of sympathetic activity limit the conclusions that we can draw regarding the mechanisms that underlie the relative reduction in flare response post-MBSR training. Finally, we did not collect self-report measures of perceived stress in response to the TSST and, consequently, must rely on cortisol levels as a proxy for the induction of psychological stress.

Nonetheless, the results of this study emphasize that the difference in the stress-buffering abilities between mindfulness training and other well-being promoting activities is subtle. Practice in both interventions predicted a decrease in diurnal cortisol, but MBSR practice alone predicted a more salubrious diurnal cortisol rhythm following training. A posttraining, seasonally-adjusted reduction in inflammation, however, was specific to mindfulness training, which suggests that mindfulness may be more effective in relieving symptoms related to inflammation than other well-being promoting activities. The fact that a post-training group difference in flare size was found, in the absence of a group difference in blister-fluid cytokine levels, may indicate that individuals with inflammatory diseases that have a strong neurogenic component would benefit more from mindfulness training than from other group-based behavioral interventions that do not promote mindfulness. Indeed, the benefit of mindfulness to individuals with chronic, neurogenic, skin inflammation has been previously demonstrated. Jon Kabat-Zinn and colleagues (1998) reported a 4-fold increase in clearing rate of psoriasis lesions when mindfulness practice was added to treatment as usual. We corroborate this finding in a non-clinical population and now have evidence for the specific efficacy of mindfulness training in reducing the responsivity of physiological processes characteristic of a wide range of chronic conditions, as well as promising hypotheses regarding the molecular mechanisms influenced by mindfulness practice that may lead to symptom alleviation.

\section{Acknowledgments}

We gratefully acknowledge Dr. Ned Kalin's staff for their assistance with the salivary cortisol assays and Dr. James Davis for his time and medical oversight of participant safety. This work was supported by funding from NCCAM \#U01AT002114-01A1 to Antoine Lutz, NIMH P50-MH069315 to Richard J. Davidson, the Fetzer Institute, and gifts from Adrianne and Edwin Cook-Ryder, Bryant Wangard, Keith and Arlene Bronstein, and the John W. Kluge Foundation.

\section{References}

Abercrombie HC, Giese-Davis J, Sephton S, Epel ES, Turner-Cobb JM, Spiegel D. Flattened cortisol rhythms in metastatic breast cancer patients. Psychoneuroendocrinology. 2004; 29:1082-1092. [PubMed: 15219660]

Adam EK, Gunnar MR. Relationship functioning and home and work demands predict individual differences in diurnal cortisol patterns in women. Psychoneuroendocrinology. 2001; 26:189-208. [PubMed: 11087964]

Arck PC, Slominski A, Theoharides TC, Peters EMJ, Paus R. Neuroimmunology of stress: Skin takes center stage. J Invest Dermatol. 2006; 126:1697-1704. [PubMed: 16845409]

Banik RK, Sato J, Giron R, Yajima H, Mizumura K. Interactions of bradykinin and norepinephrine on rat cutaneous nocioceptors in both normal and inflamed conditions in vitro. Neurosci Res. 2004; 49:421-425. [PubMed: 15236868]

Banik RK, Sato J, Yajima H, Mizumura K. Differences between the Lewis and Sprague-Dawley rats in chronic inflammation induced norepinephrine sensitivity of cutaneous C-fiber nociceptors. Neurosci Lett. 2001; 299:21-24. [PubMed: 11166928]

Barnes, PM.; Bloom, B.; Nahin, RL. National Health Statistics Reports Number 12. U.S. Department of Health and Human Services; Complementary and Alternative Medicine Use Among Adults and 
Children: United States, 2007. Publication No. (PHS) 2009-1250; http://nccam.nih.gov/news/ camstats/2007)

Barrino AM, Voltolini S, Fiaschi D, Pellegrini S, Bignardi D, Minale P, Troise C, Maura E. Chronic urticaria: importance of a medical-psychological approach. Eur Ann Allergy Clin Immunol. 2006; 38:149-152. [PubMed: 17058846]

Bender, AE.; Bender, DA. A Dictionary of Food and Nutrition. New York: Oxford University Press; 1995. Body Surface Area.

Bishop SR, Lau M, Shapiro S, Carlson L, Anderson ND, Carmody J, Segal ZV, Abbey S, Speca M, Velting D, Devins G. Mindfulness: A proposed operational definition. Clin Psychol Sci Prac. 2004; 11:230-241.

Bjerring P, Arendt Nielsen L. A quantitative comparison of the effect of local analgesics on argon laser induced cutaneous pain and on histamine induced wheal, flare and itch. Acta Derm Venereol. 1990; 70:126-131. [PubMed: 1969196]

Black PH. Stress and the inflammatory response: a review of neurogenic inflammation. Brain Behav Immun. 2002; 16:622-653.9. [PubMed: 12480495]

Arck P, Paus R. From the brain-skin connection: the neuroendocrine-immune misalliance of stress and itch. Neuroimmunomodulation. 2006; 13:347-356. [PubMed: 17709957]

Bockelbrink A, Heinrich J, Schäfer I, Zutavern A, Borte M, Herbarth O, Schaaf B, von Berg A, Schäfer T. LISA Study Group. Atopic eczema in children: another harmful sequel of divorce. Allergy. 2006; 61:1397-1402. [PubMed: 17073868]

Bower JE, Ganz PA, Dickerson SS, Petersen L, Aziz N, Fahey JL. Diurnal cortisol rhythm and fatigue in breast cancer survivors. Psychoneuroendocrinology. 2005; 30:92-100. [PubMed: 15358446]

Brydon L, Walker C, Wawrzyniak A, Whitehead D, Okamura H, Yajima J, Tsuda A, Steptoe A. Synergistic effects of psychological and immune stressors on inflammatory cytokine and sickness responses in humans. Brain Behav Immun. 2009; 23:217-224. [PubMed: 18835437]

Bunker CB, Cerio R, Bull HA, Evans J, Dowd PM, Foreman JC. The effect of capsaicin application on mast cells in normal human skin. Agents Actions. 1991; 33:195-196. [PubMed: 1897439]

Buske-Kirschbaum A, Ebrecht M, Kern S, Hellhammer DH. Endocrine stress responses in TH1mediated chronic inflammatory skin disease (psoriasis vulgaris) - do they parallel stress-induced endocrine changes in TH2-mediated inflammatory dermatoses (atopic dermatitis)? Psychoneuroendocrinology. 2006; 31:439-446. [PubMed: 16359823]

Buske-Kirschbaum A, Geiben A, Höllig H, Morschhäuser E, Hellhammer D. Altered responsiveness of the hypothalamaic-pituitary-adrenal axis and the sympathetic adrenomedullary system to stress in patients with atopic dermatitis. J Clin Endocrinol Metab. 2002; 87:4245-4241. [PubMed: 12213879]

Buske-Kirschbaum A, Hellhammer DH. Endocrine and immune responses to stress in chronic inflammatory skin disorders. Ann NY Acad Sci. 2003; 992:231-240. [PubMed: 12794062]

Buske-Kirschbaum A, Kern S, Ebrecht M, Hellhammer D. Altered distribution of leukocyte subsets and cytokine production in response to acute psychological stress in patients with psoriasis vulgaris. Brain, Behav Immun. 2007; 21:92-99. [PubMed: 16714097]

Carlson LE, Speca M, Patel KD, Goodey E. Mindfulness-based stress reduction in relation to quality of life, mood, symptoms of stress and levels of cortisol, dehydroepiandrosterone sulfate (DHEAS) and melatonin in breast and prostate cancer outpatients. Psychoneuroendocrinology. 2004; 29:448-474. [PubMed: 14749092]

Carmody J, Baer RA. Relationships between mindfulness practice and levels of mindfulness, medical and psychological symptoms and well-being in a mindfulness-based stress reduction program. $\mathrm{J}$ Behav Med. 2008; 31:23-33. [PubMed: 17899351]

Carroll JE, Low CA, Prather AA, Cohen S, Fury JM, Ross DC, Marsland AL. Negative affective responses to a speech task predict changes in interleukin (IL)-6. Brain Behav Immun. 2011; 25:232-238. [PubMed: 20888901]

Chambers R, Gullone E, Allen NB. Mindful emotion regulation: An integrative review. Clin Psychol Rev. 2009; 29:560-572. [PubMed: 19632752]

Church MK, Clough GF. Human skin mast cells: in vitro and in vivo studies. Ann Allergy Asthma Immunol. 1999; 83:471-475. [PubMed: 10582733] 
Church MK, Lowman MA, Rees PH, Benyon RC. Mast cells, neuropeptides and inflammation. Agents Actions. 1989; 27:8-16. [PubMed: 2473641]

Cohen L, Cole SW, Sood AK, Prinsloo S, Kirschbaum C, Arevalo JM, Jennings NB, Scott S, Vence L, Wei Q, Kentor D, Radvanyi L, Tannir N, Jonasch E, Tamboli P, Pisters L. Depressive symptoms and cortisol rhythmicity predict survival in patients with renal cell carcinoma: role of inflammatory signaling. PLOS One. 2012:7. (epub ahead of publication).

Cua DJ, Tato CM. Innate IL-17-producing cells: the sentinels of the immune system. Nat Rev Immunol. 2010; 10:479-489. [PubMed: 20559326]

Cuesta MC, Quintero L, Pons H, Suarez-Roca H. Substance P and calcitonin gene-related peptide increase IL-1 beta, IL-6 and TNF alpha secretion from human peripheral blood mononuclear cells. Neurochem Int. 2002; 40:301-306. [PubMed: 11792459]

Derogatis, LR. SCL-90-R administration, scoring and procedures manual II. Clinical Psychometric Research; Maryland: 1983.

Dickerson SS, Gable SL, Irwin MR, Aziz N, Kemeny ME. Social-evaluative threat and proinflammatory cytokine regulation: an experimental laboratory investigation. Psychol Sci. 2009; 20:1237-1244. [PubMed: 19754527]

Dickerson SS, Kemeny ME. Acute stressors and cortisol responses: a theoretical integration and synthesis of laboratory research. Psychol Bull. 2004; 130:355-391. [PubMed: 15122924]

Drummond PD. Noradrenaline increases hyperalgesia to heat in skin treated by capsaicin. Pain. 1995; 60:311-315. [PubMed: 7596627]

Gibbs BF, Wierecky J, Welker P, Henz BM, Wolff HH, Grabbe J. Human skin mast cells rapidly release preformed and newly generated TNF-alpha and IL-8 following stimulation with anti-IgE and other secretagogues. Exp Dermatol. 2001; 10:312-320. [PubMed: 11589728]

Glaser R, Kiecolt-Glaser JK, Marucha PT, MacCallum RC, Laskowski BF, Malarkey WB. Stressrelated changes in proinflammatory cytokine production in wounds. Arch Gen Psychiat. 1999; 56:450-456. [PubMed: 10232300]

Gregg JA, Callaghan GM, Hayes SC, Glenn-Lawson JL. Improving diabetes self-management through acceptance, mindfulness, and values: a randomized controlled trial. J Consult Clin Psychol. 2007; 75:336-343. [PubMed: 17469891]

Grossman P, Van Dam NT. Mindfulness by any other name: Trials and tribulations of sati in western psychology and science. Contemporary Buddhism. 2011; 11:219-239.

Grossman P, Tiefenthaler-Gilmer U, Raysz A, Kesper U. Mindfulness training as an intervention for fibromyalgia: evidence of postintervention and 3-year follow-up benefits in weil-being. Psychother Psychosom. 2007; 76:226-233. [PubMed: 17570961]

Gruenewald TL, Kemeny ME, Aziz N, Fahey JL. Acute threat to the social self: shame, social selfesteem, and cortisol activity. Psychosom Med. 2004; 66:915-924. [PubMed: 15564358]

Härle P, Straub RH, Wiest R, Mayer A, Schölmerich J, Atzeni F, Carrabba M, Cutolo M, Sarzi-Puttini $\mathrm{P}$. Increase of sympathetic outflow measured by neuropeptide $\mathrm{Y}$ and decrease of the hypothalamicpituitary-adrenal axis tone in patients with systemic lupus erythematosus and rheumatoid arthritis: another example of uncoupling of response systems. Ann Rheum Dis. 2006; 65:51-56. [PubMed: 15941834]

Hart A, Kamm MA. Review article: mechanisms of initiation and perpetuation of gut inflammation by stress. Aliment Pharmacol Ther. 2002; 16:2017-2028. [PubMed: 12452934]

Helme RD, McKernan S. Neurogenic flare responses following topical application of capsaicin in humans. Ann Neurol. 1985; 18:505-509. [PubMed: 4073843]

Izumi H, Karita K. Axon reflex flare evoked by nicotine in human skin. Jpn J Physiol. 1992; 42:721730. [PubMed: 1491498]

Jha AP, Stanley EA, Kiyonaga A, Wong L, Gelfand L. Examining the protective effects of mindfulness training on working memory capacity and affective experience. Emotion. 2010; 10:54-64. [PubMed: 20141302]

Kabat-Zinn J. An outpatient program in behavioral medicine for chronic pain patients based on the practice of mindfulness meditation: theoretical considerations and preliminary results. Gen Hosp Psychiatry. 1982; 4:33-47. [PubMed: 7042457] 
Kabat-Zinn, J. Full catastrophe living: Using the wisdom of your body and mind to face stress, pain and illness. Delacorte Press; New York: 1990.

Kabat-Zinn J, Wheeler E, Light T, Skillings A, Scharf MJ, Cropley TG, Hosmer D, Bernhard JD. Influence of a mindfulness meditation-based stress reduction intervention on rates of skin clearing in patients with moderate to severe psoriasis undergoing phototherapy (UVB) and photochemotherapy (PUVA). Psychosom Med. 1998; 60:625-632. [PubMed: 9773769]

Kabat-Zinn J. Some reflections on the origens of MBSR, skillful means and the trouble with maps. Contemporary Buddhism. 2011; 11:281-306.

Keller J, Flores B, Gomez RG, Solvason HB, Kenna H, Williams GH, Schaatzberg AF. Cortisol circadian rhythm alterations in psychotic major depression. Biol Psychiatry. 2006; 60:275-281. [PubMed: 16458262]

Kemeny ME, Foltz, Cavanagh JF, Cullen M, Giese-Davis J, Jennings P, Rosenberg EL, Gillath O, Shaver PR, Wallace BA, Ekman P. Contemplative/emotion training reduces negative emotional behavior and promotes prosocial responses. Emotion. 2011:1-13. [PubMed: 21058841]

Kim HS, Cho DH, Kim HJ, Lee JY, Cho BK, Park HJ. Immunoreactivity of corticotropin-releasing hormone, adrenocorticotropic hormone and alpha-melanocyte-stimulating hormone in alopecia areata. Exp Dermatol. 2006; 15:515-522. [PubMed: 16761960]

Kirschbaum C, Pirke KM, Hellhammer DH. The 'Trier Social Stress Test'--a tool for investigating psychobiological stress responses in a laboratory setting. Neuropsychobiology. 1993; 28:76-81. [PubMed: 8255414]

Kleyn CE, Schneider L, Saraceno R, Mantovani C, Richards HL, Fortune DG, Cumberbatch M, Dearman RJ, Terenghi G, Kimber I, Griffiths CE. The effects of acute social stress on epidermal Langerhans' cell frequency and expression of cutaneous neuropeptides. J Invest Dermatol. 2008; 128:1273-1279. [PubMed: 17989731]

Kumari M, Shipley M, Stafford M, Kivimaki M. Association of diurnal patterns in salivary cortisol with all-cause and cardiovascular mortality: findings from the Whitehall II study. J Clin Endocrinol Metab. 2011; 96:1478-1485. [PubMed: 21346074]

Kupper TS, Fuhlbrigge RC. Immune surveillance in the skin: mechanisms and clinical consequences. Nat Rev Immunol. 2004; 4:211-222. [PubMed: 15039758]

Lin Q, Zou X, Fang L, Willis WD. Sympathetic modulation of acute cutaneous flare induced by intradermal injection of capsaicin in anesthetized rats. J Neurophysiol. 2003; 89:853-861. [PubMed: 12574463]

Liu LY, Coe CL, Swenson CA, Kelly EA, Kita H, Busse WW. School examinations enhance airway inflammation to antigen challenge. Am J Respir Crit Care Med. 2002; 165:1062-1067. [PubMed: 11956045]

Lotz M, Vaughan JH, Carson DA. Effect of neuropeptides on production of inflammatory cytokines by human monocytes. Science. 1988; 241:1218-21. [PubMed: 2457950]

Lytinas M, Kempuraj D, Huang M, Boucher W, Esposito P, Theoharides TC. Acute stress results in corticotropin-releasing hormone sectretion, mast cell activation, and vascular permeability, an effect mimicked by intradermal corticotropin-releasing hormone and inhibited by histamine-1 receptor antagonists. Int Arch Allergy Immunol. 2003; 130:224-231. [PubMed: 12660427]

Ma SH, Teasdale JD. Mindfulness-based cognitive therapy for depression: replication and exploration of differential relapse prevention effects. J Consult Clin Psychol. 2004; 72:31-40. [PubMed: 14756612]

MacCoon DG, Imel ZE, Rosenkranz MA, Sheftel JG, Weng HY, Sullivan JC, Bonus KA, Stoney CM, Salomons TV, Davidson RJ, Lutz A. The validation of an active control intervention for Mindfulness Based Stress Reduction (MBSR). Behav Res Ther. 2012; 50:3-12. [PubMed: 22137364]

Matthews K, Schwartz J, Cohen S, Seeman T. Diurnal cortisol decline is related to coronary calcification: CARDIA study. Psychosom Med. 2006; 68:657-661. [PubMed: 17012518]

McArthur JC, Stocks A, Hauer P, Cornblath DR, Griffin JW. Epidermal nerve fiber density: Normative reference range and diagnostic efficiency. Arch Neurol. 1998; 55:1513-1520. [PubMed: 9865794] 
Okayama Y, Ono Y, Nakazawa T, Church MK, Mori M. Human skin mast cells produce TNF-alpha by substance P. Int Arch Allergy Immunol. 1998; 117(Suppl 1):48-51. [PubMed: 9758897]

Pace TW, Negi LT, Adame DD, Cole SP, Sivilli TI, Brown TD, Issa MJ, Raison CL. Effect of compassion meditation on neuroendocrine, innate immune and behavioral responses to psychosocial stress. Psychoneuroendocrinology. 2009; 34:87-98. [PubMed: 18835662]

Park SH, Hsiao GY, Hwang GT. Role of substance P and calcitonin gene-related peptide in the regulation of interleukin- 8 and monocyte chemotactic protein- 1 expression in human dental pulp. Int Endod J. 2004; 37:185-192. [PubMed: 15009408]

Pavlovic S, Daniltchenko M, Tobin DJ, Hagen E, Hunt SP, Klapp BF, Arck PC, Peters EM. Further exploring the brain-skin connection: stress worsens dermatitis via substance P-dependent neurogenic inflammation in mice. J Invest Dermatol. 2008; 128:434-446. [PubMed: 17914449]

Peters E, Handjiski B, Kuhlmei A, Hagen E, Bielas H, Braun A, Klapp BF, Paus R, Arck PC. Neurogenic inflammation in stress-induced termination of murine hair growth is promoted by nerve growth factor. Am J Pathol. 2004; 165:259-271. [PubMed: 15215181]

Peters E, Ericson ME, Hosoi J, Seiffert K, Hordinsky MK, Ansel JC, Paus R, Scholzen TE. Neuropeptide control mechanisms in cutaneous biology: physiological and clinical significance. $\mathbf{J}$ Invest Dermatol. 2006; 126:1937-1947. [PubMed: 16912691]

Petersen LJ, Church MK, Skov PS. Histamine is released in the wheal but not the flare following challenge of human skin in vivo: a microdialysis study. Clin Exp Allergy. 1997; 27:284-295. [PubMed: 9088655]

Pradhan EK, Baumgarten M, Langenberg P, Handwerger B, Gilpin AK, Magyari T, Hochberg MC, Berman BM. Effect of mindfulness-based stress reduction in rheumatoid arthritis patients. Arthritis Rheumat. 2007; 57:1134-1142. [PubMed: 17907231]

Pruessner J, Kirschbaum C, Meinlschmid G, Hellhammer D. Two formulas for computation of the area under the curve represent measures of total hormone concentration versus time-dependent change. Psychoneuroendocrinology. 2003; 28:916-931. [PubMed: 12892658]

Rohleder N, Wolf JM, Herpfer I, Fiebich BL, Kirschbaum C, Lieb K. No response of plasma substance $\mathrm{P}$, but delayed increase of interleukin-1 receptor antagonist to acute psychosocial stress. Life Sci. 2006; 78:3082-3089. [PubMed: 16414081]

Rosenkranz MA. Substance $\mathrm{P}$ at the nexus of mind and body in chronic inflammation and affective disorders. Psychol Bull. 2007; 133:1007-1037. [PubMed: 17967092]

Saint-Mezard P, Chavagnac C, Bosset S, Ionescu M, Peyron E, Kaiserlian D, Nicolas JF, Bérard F. Psychologial stress exerts an adjuvant effect of skin dendritic cell functions in vivo. J Immunol. 2003; 171:4073-4080. [PubMed: 14530328]

Sato J, Suzuki S, Iseki T, Kumazawa T. Adrenergic excitation of cutaneous nocioceptors in chronically inflamed rats. Neurosci Lett. 1993; 164:225-228. [PubMed: 8152606]

Schmelz M, Luz O, Averbeck B, Bickel A. Plasma extravasation and neuropeptide release in human skin as measured by intradermal microdialysis. Neurosci Lett. 1997; 230:117-120. [PubMed: 9259478]

Scholzen T, Armstrong CA, Bunnett NW, Luger TA, Olerud JE, Ansel JC. Neuropeptides in the skin: interactions between the neuroendocrine and skin immune systems. Exp Dermatol. 1998; 7:81-96. [PubMed: 9583747]

Schommer NC, Hellhammer DH, Kirschbaum C. Dissociation between reactivity of the hypothalamuspituitary-adrenal axis and the sympathetic-adrenal-medullary system to repeated psychosocial stress. Psychosom Med. 2003; 65:450-460. [PubMed: 12764219]

Sephton SE, Sapolsky RM, Kraemer HC, Spiegel D. Diurnal cortisol rhythm as a predictor of breast cancer survival. J Natl Cancer Inst. 2000; 92:994-1000. [PubMed: 10861311]

Serra MC, Calzetti F, Ceska M, Cassatella MA. Effect of substance P on superoxide anion and IL-8 production by human PMNL. Immunology. 1994; 82:63-69. [PubMed: 7519174]

Speca M, Carlson LE, Goodey E, Angen M. A randomized, wait-list controlled clinical trial: the effect of a mindfulness meditation-based stress reduction program on mood and symptoms of stress in cancer outpatients. Psychosom Med. 2000; 62:613-622. [PubMed: 11020090] 
Spiegel D, Giese-Davis J, Taylor CB, Kraemer H. Stress sensitivity in metastatic breast cancer: analysis of hypothalamic-pituitary-adrenal axis function. Psychoneuroendocrinology. 2006; 31:1231-1244. [PubMed: 17081700]

Stawski RS, Almeida DM, Lachman ME, Tun PA, Rosnick CB, Seeman T. Associations between cognitive function and naturally occurring daily cortisol during middle adulthood: timing is everything. J Gerontol B Psychol Sci Soc Sci. 2011; 66(Suppl 1):i71-81. [PubMed: 21743054]

Stead RH, Tomioka M, Quinonez G, Simon GT, Felten SY, Bienenstock J. Intestinal mucosal mast cells in normal and nematode-infected rat intestines are in intimate contact with peptidergic nerves. Proc Nat Acad Sci U S A. 1987; 84:2975-2979.

Steptoe A, Hamer M, Chida Y. The effects of acute psychological stress on circulating inflammatory factors in humans: a review and meta-analysis. Brain Behav Immun. 2007; 21:901-912. [PubMed: 17475444]

Straub RH, Herfarth H, Falk W, Andus T, Schölmerich J. Uncoupling of the sympathetic nervous system and the hypothalamic-pituitary-adrenal axis in inflammatory bowel disease? J Neuroimmunol. 2002; 126:116-125. [PubMed: 12020963]

Thompson, C. Anxiety. In: Thompson, C., editor. The instruments of psychiatric research. Wiley; New York: 1989. p. 127-155.

Travis, JW. Wellness workbook for health professionals. Wellness Resource Center; Mill Valley, CA: 1977.

Uter W, Hegewald J, Kränke B, Schnuch A, Gefeller O, Pfahlberg A. The impact of meteorological conditions on patch test results with 12 standard series allergens (fragrances, biocides, topical ingredients). Br J Dermatol. 2008; 158:734-739. [PubMed: 18284398]

Welk U, Herforth A, Kolb-Bachofen V, Deinzer R. Acute stress induces proinflammatory signaling at chronic inflammation sites. Psychocom Med. 2008; 70:906-912.

Wright RJ, Cohen RT, Cohen S. The impact of stress on the development and expression of atopy. Curr Opin Allergy Clin Immunol. 2005; 5:23-29. [PubMed: 15643340] 


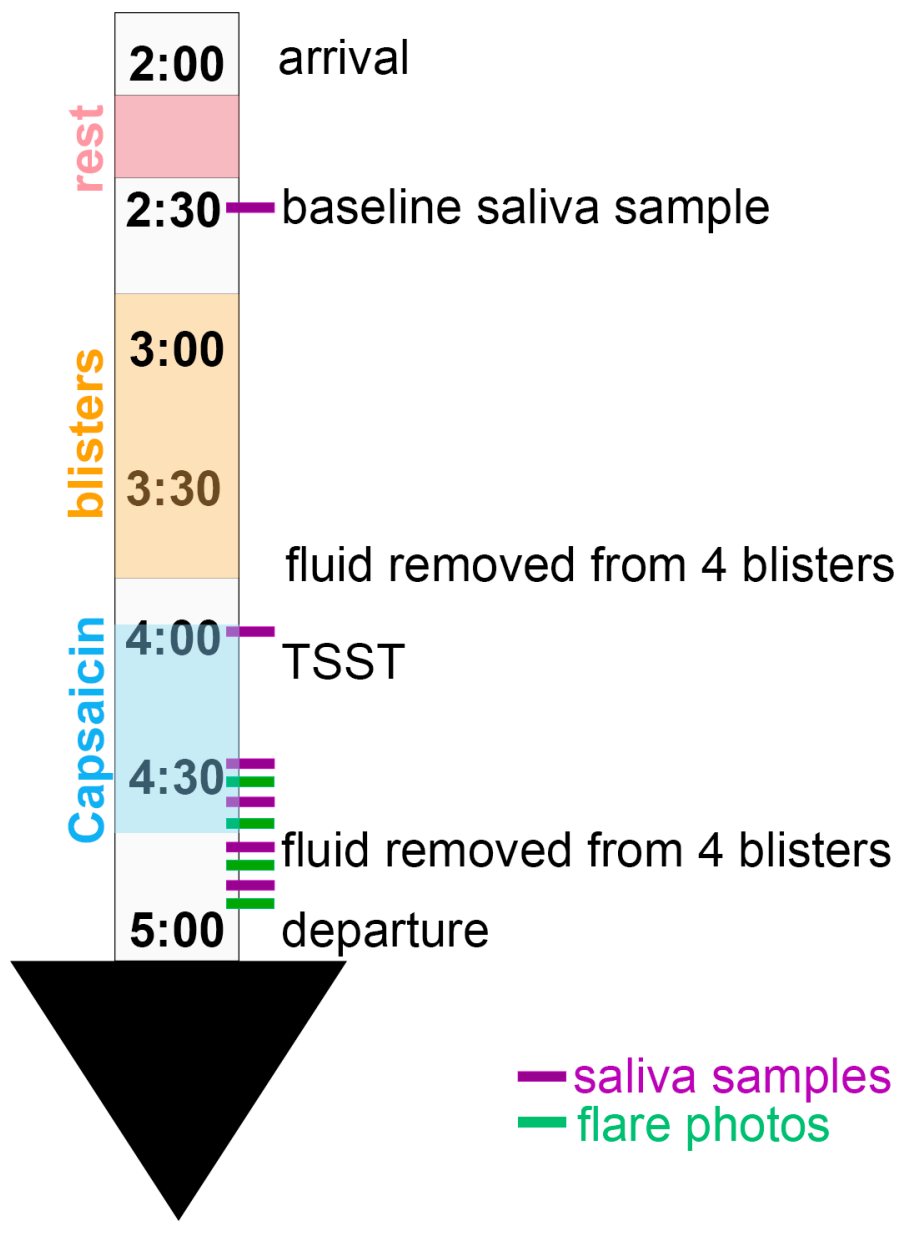

Figure 1.

An illustration of the experimental design and timing of the collection of the outcome measures. 


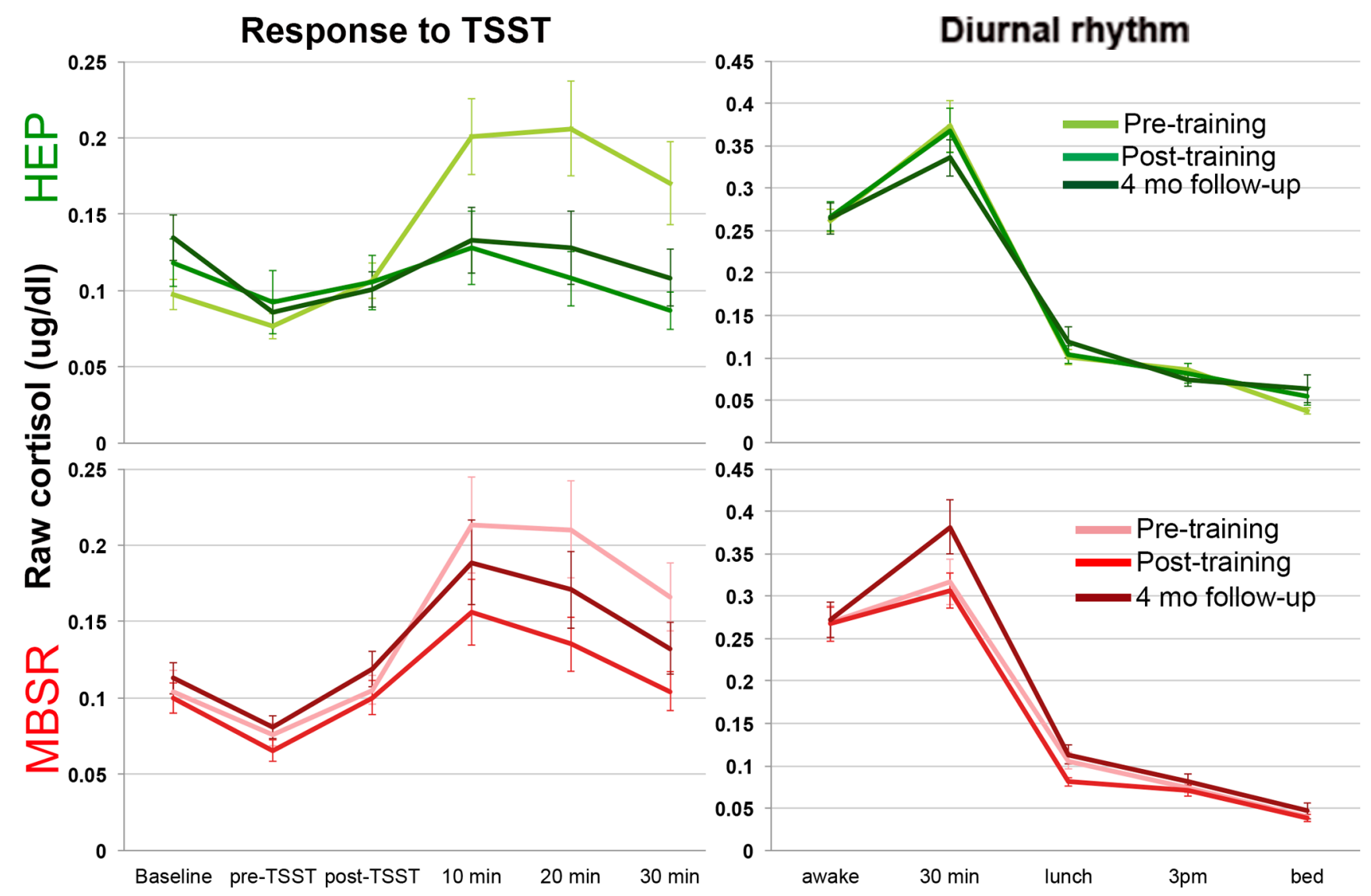

Figure 2.

Raw cortisol data showing (a) response to the TSST and (b) diurnal cortisol rhythm for each group at each assessment. 

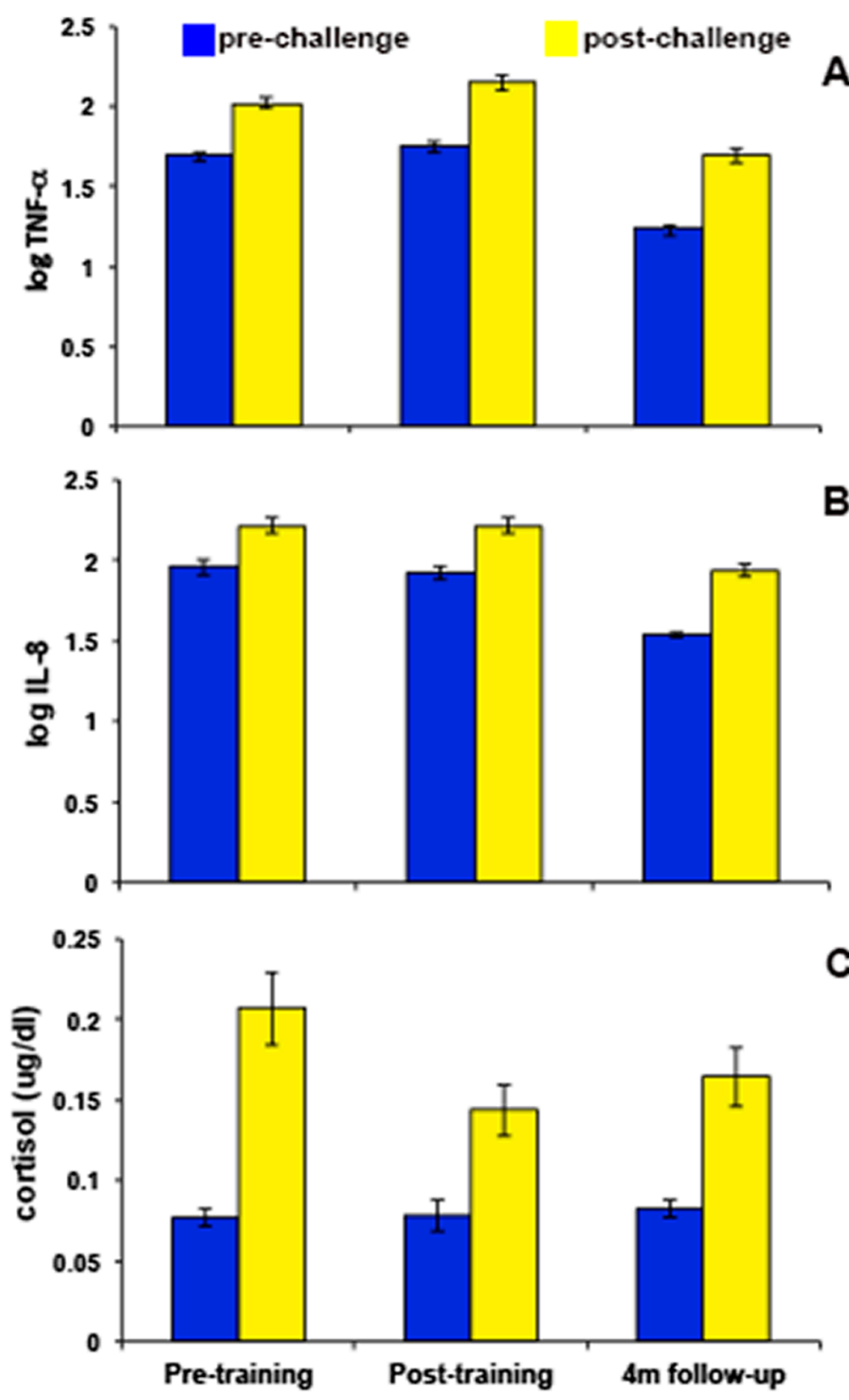

Figure 3. Blister fluid cytokine and salivary cortisol response to capsaicin application and stress (a) Increases in blister fluid TNF-a from pre to post-challenge at T1 (t(46) $=-8.09, p<$. $001), \mathrm{T} 2(t(42)=-8.89, p<.001)$, and T3 $(t(46)=-12.00, p<.001)$. (b) Increases in blister fluid IL-8 from pre- to post-challenge at T1 $(t(41)=-6.33, p<.001)$, T2 $(t(41)=-7.99, p$ $<.001)$ and T3 $(t(44)=-10.54, p<.001)$. (c). Increases in salivary cortisol from pre- to post-challenge at T1 $(t(47)=-6.01, p<.001), \mathrm{T} 2(t(42)=-4.21, p<.001)$, and T3 $(t(45)=$ $-4.73, p<.001)$. Error bars represent standard error of the mean. 


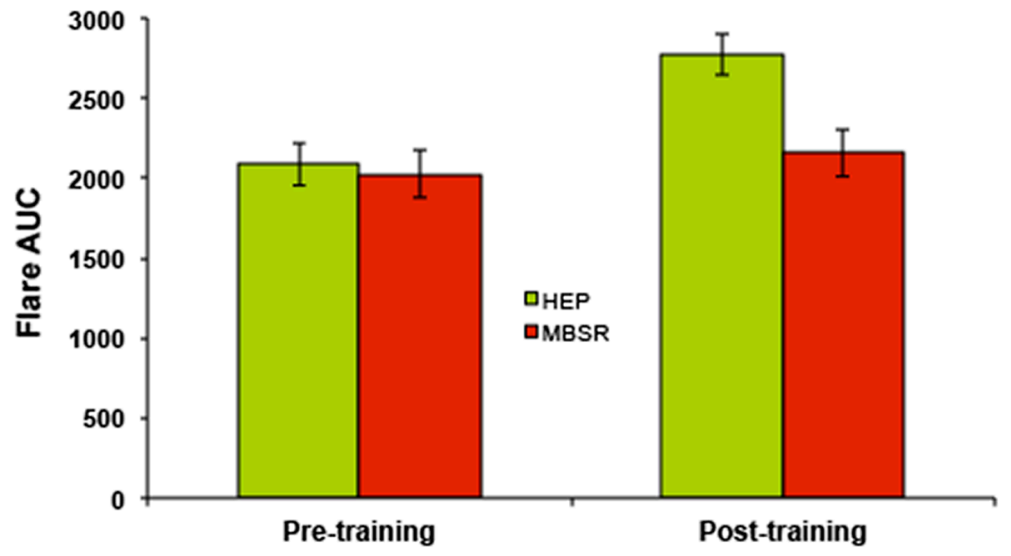

Figure 4. Effects of intervention and time on flare size

Flare size increased significantly from $\mathrm{T} 1$ to $\mathrm{T} 2(F(1,27)=31.74, p<.001)$. In addition, a significant group $\times$ time interaction was observed $(F(1,27)=10.07, p=.004)$, such that mean flare size for the HEP group at T2 was larger than that of the MBSR group. Error bars represent standard error of the mean. 

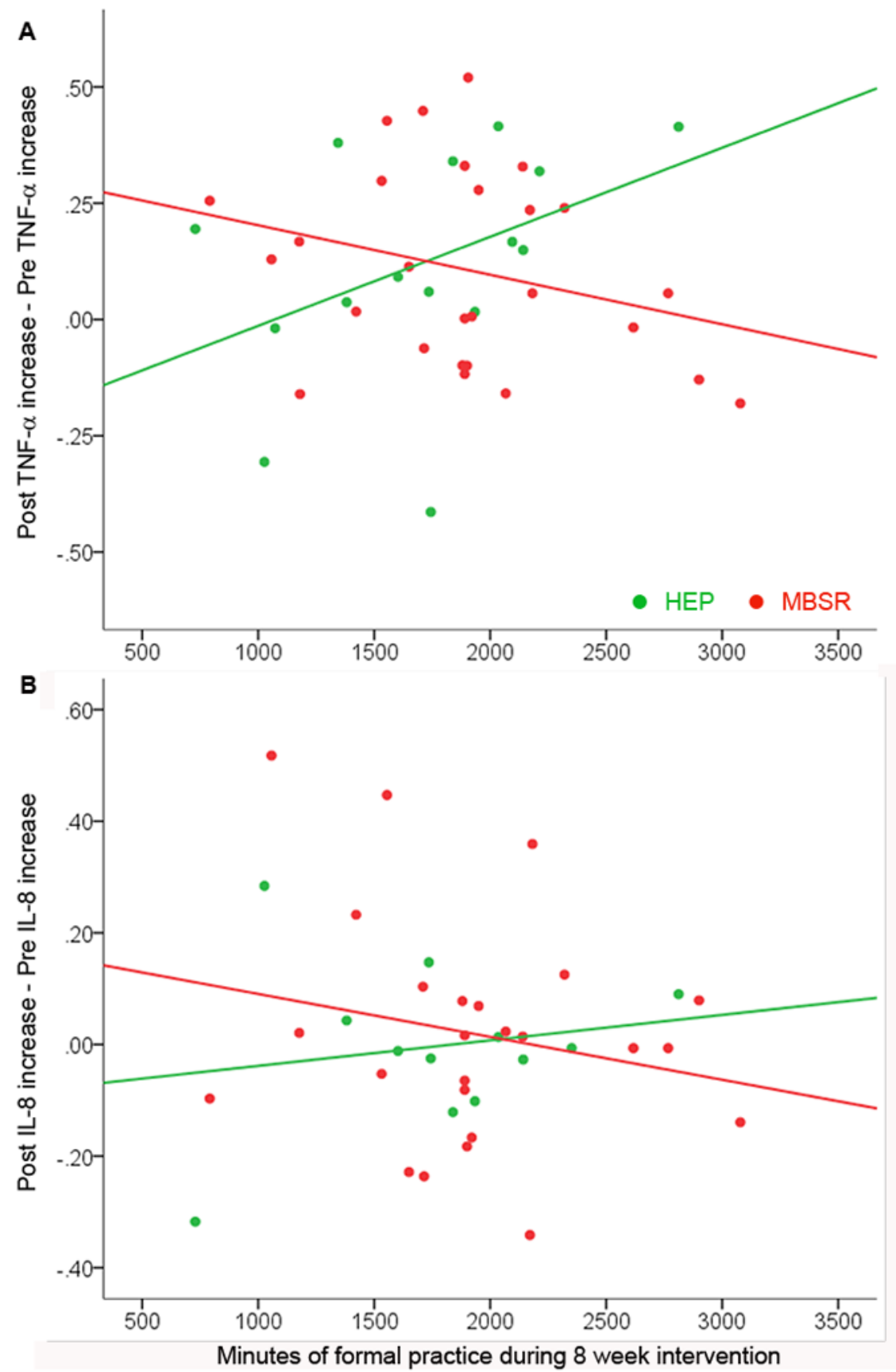

Figure 5. Relationship between practice and blister fluid cytokine changes from pre- to postintervention differs by group

We observed interactions between group and practice in relation to blister fluid cytokine levels (TNF-a: $s r=-.35, p=.028$; IL-8: $s r=-.17, p=.334$ ). In the MBSR group (red), number of minutes practiced during the 8 -wk intervention is (non-significantly) negatively correlated with the reduction in blister fluid (a) TNF-a (MBSR: $r=-.28, p=.16$; HEP: $r=$. $42, p=.12$ ) and (b) IL-8 levels (MBSR: $r=-.20, p=.33$; HEP: $r=.17, p=.59$ ) from T1 to $\mathrm{T} 2$, whereas these relationships are positive for the HEP group (green). 